\title{
A Study on the Practice of "Internet + Double Creation" Talent Training Model--Take the Media Course as an Example
}

\author{
Xiaodan $\mathrm{Shi}^{1,}$ a and Xinwen $\mathrm{Bi}^{1, \mathrm{~b}^{*}}$ \\ ${ }^{1}$ No. 3999 East Binjiang Road, Jilin, Jilin, China \\ a85095462@qq.com, b52600613@qq.com,
}

(1. Beihua University Information Technology and Media Institute , Jilin 132011)

Keywords: Internet + double creation; Media courses; Talent training model

\begin{abstract}
The arrival of the times, "Internet +", has speeded up the process of education informatization. Based on it, exploring the new methods and approaches of innovative and career-creating talents has become the key issues which colleges and universities are faced with at this stage.

Based on the connotation of double- creation talents, this study draws the experience from the teaching methods such as Flipped Classroom and Task-Driven method, which is to better analyze and design the "Internet + Double Creation" talent training mode. On the other hand, it confirms the validity of the talent training mode by the quasi - experimental research method, which can provide reference for the training of the double - creation talents in colleges and universities.

In the context of the rapid development of information and communication technology, the concept of "Internet + " has been quickly responded to by all fields. It created new ecology in various fields. "Internet + " era has accelerated the process of education information, and "Internet + education" is one of the most popular fields. Followed by it, a variety of new forms of education, such as MOOC, SPOC, flip classroom, wisdom Education and so on, have come into use. The result is that technology has deep impact on teaching form and teaching philosophy and other aspects rather than being a simple tool or the elements of creating the teaching environment,

"Public innovation, multi people Entrepreneurship" is the major development concept which Eighth Plenary Session has presented. It is also an important measure of promoting the implementation of innovation-driven development strategy. The hit of "Double creation" has also brought new opportunities for innovation and entrepreneurship education in colleges and universities. Relying on the Internet, deepening innovation and entrepreneurship education in colleges and universities to enhance the ability of innovation and entrepreneurship has become inevitable.
\end{abstract}

\section{An Analysis of "Internet + Double Creation" Talent Training Model}

Double Connotation of Talent. Innovative talent refers to those who possess the spirit, the awareness, and the ability of innovation, and who are able to achieve innovative results ${ }^{[1]}$;Entrepreneurial talent is someone who knows certain professional technics to some degree, and who has the abilities of pioneering and organizing and the qualities of entrepreneur that is good at finding business opportunities and making profit by creative production or business activities ${ }^{[2]}$.

On the whole, the double pioneering talent refers to the people who have innovative and entrepreneurial consciousness, and be able to discover and master the entrepreneurial opportunity. They can work alone or cooperate with others, create their own business and make profit by creatively using the existing knowledge. The comprehensive quality of the double-talents is embodied in three aspects: double consciousness, double ability and double creation personality. Double creative consciousness is the starting point of double-talent training, and is the driving force of innovation and entrepreneurial activities. Double consciousness is the result of internal and external factors. Internal factors include curiosity, interest and other factors. External factors include learning tasks, work pressure and so on. Double ability includes a lot of quality features, such as solid professional knowledge and skills, rich imagination, keen insight, the courage of asking 
questions and questioning, being good at risk-taking and solving problems independently. Double personality reflects the characteristics of non-intellectual factors, such as strong sense of social responsibility, strong social skills, high level of management, the ability of communicating and cooperating with others.

Talent Training Mode Connotation. The Ministry of Education has pointed out in the document on "Deepening the Teaching Reform and Training High Quality Talents to Meet the Needs of the 21st Century": "The pattern of personnel training is the way which schools build to construct knowledge, ability, quality structure and the way to achieve this structure. It fundamentally provides for the characteristics of talent and embodies the educational ideas and educational concepts " [3].

The basic elements of the talent training model include: training objectives, teaching content, training methods and evaluation system. That is, personnel training is about training what kind of people, using what to train people, how to train people, how are the people who are trained these four issues to start. The training objectives elements is to solve the "to train what kind of person" problem, giving standers on knowledge, quality, ability and other aspects of the request to the training talents .Teaching content is to solve the problem of "using what to train people ",which mainly related to training systems, training programs, professional settings, curriculum system and so on. Training methods is to solve the problem " how to train people ", which mainly related to training methods and teaching methods. Evaluation system element is to solve the problem " how are the people who are trained ", which mainly related to the quality of people trained assessment and evaluation ${ }^{[4]}$.

Principles of Construction of "Internet + Double Creation" Talent Training Model

In "Internet + double" talent training mode, the Internet is one of the resources which can be used. And the other is the factors which influence the educational ideas and the methods; double creation is not only a model to build the value orientation, but also is the ultimate goal of the training. The principle of construction should follow the principle of average people training. But it should also reflect the particularity based on the Internet. In general, it can be divided into systemic principles, serving principles and open principles.

Systematic Principle. The construction of the "Internet + Double Creation" Model should be based on the basic elements of the average talents training model, aiming at training students' double-creation ability, combining with the new educational forms in the background of the Internet, deeply analyzing the training objectives, teaching contents, training methods and evaluation system and the mutual relations among them, so that we can make it a scientific and systematic talents training model.

Serving Principle. Talent training is not only to meet the needs of individual development of students but also to meet the needs of the society for talents. Therefore, the construction of the training should consider both the students and the society. On the one hand, we should take the students as the main body and respect the characteristics of the students, to create a suitable environment for the double- creation students. On the other hand, combing with the market environment and social needs, training in line with social development needs of the double talent.

Open Principle. Although the training of double-creation talents is based on professional knowledge and skills, the focuses are on the people's abilities of realizing problems, solving problems, enterprising spirit, and communicating skills and other aspects of the overall qualities. The traditional knowledge-based teaching mode is difficult to meet the needs of the training of double-creation talents. Therefore, we should fully learn from domestic and foreign success stories, broaden the educational ideas. For example, we should establish of a teaching of connecting the schools with the enterprises, or establish the internship base. Stimulate the development of their abilities by conducting experiments.

In addition, the Internet provides a broader space for the development of education so that this training can be more opened and have wider views. We can explore new training methods under the help of the Internet. 


\section{Practice of "Internet + Double Creation" Talent Training Mode in Media Courses}

Analysis of Media Courses. With the new media technology gradually into people's lives, media majors are more and more important and popular, such as digital media, educational technology and so on. Most of these courses revolve around the structure of the media curriculum system, including print media, three dimension, film and television media, and online media. Specific courses are: digital image processing technology, interactive multimedia technology, non-linear editing technology, video effects, web design and production.

The aim of these media courses is to request the students to have a good command of the operating skills, but to train the students' abilities is also important. Students should not only have the ability to produce works, but also have the ability to solve problems, innovation, communication skills, teamwork and other comprehensive quality.

Practice of "Internet + Double Creation" Talent Training Mode. Design of "Internet + Double Creation" Talent Training Model. Double creative ability includes three aspects: sense of double creation, double creation abilities and the personalities of double creation. They are the cores. all the elements such as the training objectives ,teaching content, training methods and rating system should be designed on the ability. Specifically embodied:

\section{"Internet + Double" Talent Training Objectives}

Those with a solid professional knowledge and skills, better comprehensive knowledge and quality; with strong learning ability, keen insight and strong problem-solving ability, and communicating skills, collaboration and management skills; innovative, entrepreneurial enthusiasm .those who have a strong curiosity about the new things and the desire to explore things of unknown things, but also should have a positive character, a strong sense of social responsibility.

\section{"Internet + Double" Talent Teaching Content}

According to the training objectives, combined with the specific subject knowledge organization of teaching content, we should pay attention to the systematic and integrity of knowledge, we should also focus on the training of learning methods and techniques, and the effective use of network learning resources. For example, on the course of the use of photoshop processing picture, teaching content of the teachers can not be limited to the operation and use of tools in the software. In order to enable students to better understand the principle of dealing with pictures, students also need to understand the composition, color and other knowledge of artistic design principles. In addition, we should make full use of the network of excellent learning resources. teachers can sort out the learning resources before teaching and give them to the targeted students, guide students to use learning resources independently, to solve the problem.

\section{"Internet + Double Creation" Talent Training}

Make full use of the Internet + background videos, online learning resources and methods. Meet the needs of the students' personalized learning, and allow the students to study anywhere and anytime. Help students gain the knowledge and development. Task-driven teaching method which is based on the constructivist learning theory is carried out around the task. Students, relying on the network teaching environment, making use of learning resources, can have self-exploration and interactive collaboration learning.it can provide the experience situation and practice situation .it is an effective way to train talented people.

\section{"Internet + double" Talent Evaluation System}

The evaluation system mainly considers three problems: the dimension of evaluation, the form of evaluation and the expert composition of evaluation. The dimensions of the evaluation should be closely focused on three aspects that are double creation awareness, double creation ability, and double creation personality. The learners can be evaluated by the test, the questionnaire survey and the observation. The learner's learning process and the final works should be evaluated by the combination of the process evaluation and the summative evaluation. The experts for evaluating should not only be limited to teachers, but also those who have entrepreneurial experience because the abilities of double creation talents should be comprehensive. The entrepreneurial people who have different backgrounds, and the experts from different industries can combine their own experience to give evaluation and valuable suggestions from multiple perspectives, which is helpful 
to the development of students' ability.

Practice Process and Result Analysis. Quasi - experimental design. Taking the graphic graphics processing course as an example, and the students of educational technology institution of Beihua University as the sample, we validates the validity of the "Internet + double creation" talent training mode. The samples were randomly divided into groups, but making sure the number of the students, the proportion of men and women, the level of knowledge, the ability levels and so on are the same or similar. The experiment took three rounds of four months totally. Experimental group of students use the "Internet + double" talent training model to learn, under the guidance of the teachers, design and finish the task. The students in the control group used the traditional teaching method to study the same learning content. They are organized by the same teacher.

Teaching Process. With the traditional teaching method as the core content, the control group learn filters, channels and Mongolian and complete the corresponding exercises and homework. While teachers of the experimental group will sort out and organize the same learning target with the "Internet + double" talent training model. Students are requested to finish three double creation tasks.

Analysis of Teaching Effect. After the end of the experiment, the results of the two groups are as follows: participation rate of the experimental group at all levels is $98 \%$, among which access to national awards is $36 \%$, the provincial awards is $59 \%$, the other levels awards is $5 \%$; while the participation rate of the control group at all levels is $36 \%$, access to national awards is 0 , the provincial award is $12 \%$; the other levels is $88 \%$. We can conclude from the above data that the students who are taught under the "Internet + double" talent training model have a higher enthusiasm for innovation and entrepreneurship projects, and get a higher level of awards, and whose works get a higher degree of recognition of experts.

In addition, compared with the control group, the experimental group had more group learning, so in the competition. Their cooperation and communication are more tacit, problem-solving abilities, and collaborate abilities, organization ability and leadership are more prominent. The position and creativity of their works are more normative, and have a good value of practical application .

\section{Conclusion}

"Internet + Double Creation " talent training model enables students to improve the double awareness, double creation ability, and double creation personality. When participating the double creation task and the competition of all levels, students are more active in knowledge learning, problem solving and other aspects of the performance in the Internet environment. Meanwhile, students obtain a strong self-confidence and self-identity through the selection and promotion of the game, which lead to a higher enthusiasm for innovation and entrepreneurial task. On the other hand, the training of innovative entrepreneurship is a long-term task which needs of the perseverance of the Universities. Also the government and the whole society have the same responsibility. We need to work together to provide a better environment with the opportunity of "Internet +".

Fund Project. Beihua University Youth Project "Research on the Design and Teaching Application of Micro - course for User Experience - Taking Primary Education as an Example" ( XJQN2017023 ) One of the stage researches ; Chunhui Project of State Ministry of Education (104900150); Beihua University Youth Project "Application of case - based teaching in C language programming for professional application”. ( XJQN2016035 )

\section{References}

[1] Wang yingjie. Innovative Education for College Students from International Perspective [M].Tai Yuan : Shanxi Education Press, 2005.

[2] LIU biqiang. The Trainion Mode of Entrepreneurship Talents in British Universities and Its 
Enlightenment [J]. Higher Education Management,2014 ( 1 ) :109-110.

[3] Ministry of Education. Compilation of the First National Conference on Teaching Work in Colleges and Universities , 1998..

[4] Sun Delin. A Study on the Trainion Mode of Innovative and Entrepreneurial Diversified Talents - Based on the Perspective of "Undergraduate Teaching Project" and "Comprehensive Reform of Specialty" [M]. Beijing : Science Press,2014:23-24. 